\title{
ANÁLISE 2D E 3D DA ESTABILIDADE DA BARRAGEM DE FUNDÃO
}

\author{
2D and 3D Slope Stability Analysis of Fundão Dam
}

\author{
João Paulo Tavares SOUZA ${ }^{1}$, Nícolas Rodrigues MOURA ${ }^{2}$, Gilson de F. N. GITIRANA Jr. ${ }^{3}$
}

Recebido em 28 de fevereiro de 2019; aceito em 03 de julho de 2019; disponível on-line em 12 de fevereiro de 2020

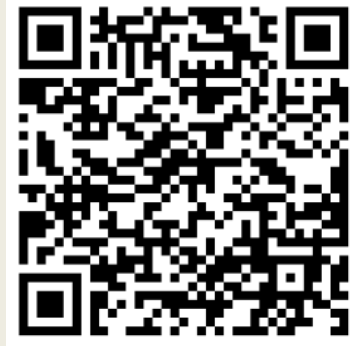

PALAVRAS CHAVE:

Barragens de rejeito; Barragem de Fundão; Análise tridimensional; Fator de Segurança; Estabilidade de taludes.

\section{KEYWORDS:}

Tailings dams;

Fundão dam;

Three-dimensional analysis;

Factor of Safety;

Slope stability.

\begin{abstract}
RESUMO: A falha da Barragem de Fundão, o maior desastre de seu tipo no mundo, foi estudada por Morgenstern et al. (2016) através de abordagens bidimensionais. A investigação realizada não apontou mecanismos de instabilidade de taludes como sendo as causas do desastre. No entanto, o formato complexo da face da barragem, com regiões côncavas e convexas, não foi considerado devido às limitações das ferramentas empregadas. Este trabalho apresenta análises bidimensionais (2D) e tridimensionais (3D), teoricamente mais rigorosas e adequadas para a geometria da barragem. As análises de estabilidade do maciço foram realizadas utilizando o Método Geral das Fatias e das Colunas (GLE), por meio do software SVSLOPE. Foram realizadas buscas por superfícies críticas 2D e 3D, ao longo de todas as zonas da estrutura. Considerando-se parâmetros de resistência drenada, observou-se que Fundão se encontraria em condições de elevada segurança, sendo o menor Fator de Segurança igual a 1,744. Valores próximos de 1,0 foram obtidos considerando rejeitos na condição não drenada, supostamente menos representativa das condições reais de campo. Os Fatores de Segurança 3D se mostraram muito próximos dos $2 D$, porém com variações significativas nas regiões côncava e convexa. Desta forma, conclui-se que o formato próximo à região do recuo exige maior atenção e análises 3D podem identificar as regiões críticas.
\end{abstract}

ABSTRACT: The failure of the Fundão Dam, the largest disaster of its kind in the world, was studied by Morgenstern et al. (2016) using two-dimensional approaches. The carried out investigation did not point to mechanisms of slope instability as the causes of the disaster. However, the complex shape of the dam and its concave and convex regions were not originally considered due to limitations of the analysis tools employed. This paper presents two-dimensional (2D) and three-dimensional (3D) analyses that are more rigorous and well suited for the Fundão dam geometry. Slope stability analyses were accomplished using the General Limit Equilibrium Method of Slices and Columns (GLE) using the SVSLOPE software. Critical slip surfaces were searched in $2 D$ and $3 D$, across the entire dam face. Drained shear strength parameters led to Factors of Safety that would indicate fairly stable conditions, with a lowest Factor of Safety of 1.744. Values close to 1.0 were obtained considering undrained conditions of the tailings, which are supposedly less representative of field conditions. The $3 D$ factors of safety were very close to the $2 D$ values, but with noticeably higher variations near the concave and convex regions. This leads to the conclusion that the dam shape near the setback region requires closer examination by means of 3D analyses that enable the identification of critical zones.

\footnotetext{
* Contato com os autores:

${ }^{1}$ E-mail: jptavs@gmail.com (J. P. S. Tavares)

Engenheiro Civil pela Universidade Federal de Goiás.

2E-mail: nicolasengmoura@gmail.com (N. R. Moura)

Engenheiro Civil, aluno de mestrado do Programa de Pós-Graduação em Geotecnia, Estruturas e Construção Civil da Escola de Engenharia Civil e Ambiental da Universidade Federal de Goiás.

${ }^{3}$ E-mail: gilsongitirana@ufg,br (G. F. N. Gitirana Jr.)

Engenheiro Civil, Ph.D, Professor Associado, Escola de Engenharia Civil e Ambiental da Universidade Federal de Goiás.
} 


\section{INTRODUÇÃO}

Rompimentos de barragens de rejeitos geram significativos prejuízos ambientais, sociais e econômicos. Um exemplo recente foi a ruptura da Barragem de Fundão, em 5 de novembro de 2015, no município brasileiro de Mariana, Minas Gerais. A corrida de rejeitos liberados pela ruptura da estrutura devastou grande parte do distrito de Bento Rodrigues, ceifou vidas e afetou o meio biótico da Bacia do Rio Doce, um dos mais importantes do país e responsável pelo abastecimento de água em parte de Minas Gerais e Espírito Santo. Desastres como esse impactam a própria indústria de mineração, um setor com parcela significativa na balança comercial nacional e com elevada geração de empregos (Vale, 2017).

O "Comitê de Especialistas para Análise da Ruptura da Barragem de Rejeitos de Fundão", aqui denominado "Painel de Investigação", apontou em seu relatório (Morgenstern et al., 2016) mecanismos de ruptura não convencionais associados com a presença de camadas de rejeitos finos onde só deveriam haver rejeitos granulares com elevada condutividade hidráulica. No entanto, observa-se no relatório publicado que as análises de estabilidade de taludes realizadas foram bidimensionais (2D), sendo que características topográficas do problema indicam a necessidade de análises tridimensionais (3D).

Destaca-se a presença do recuo construído junto à ombreira esquerda e a construção da barragem em um vale encaixado, conforme pode ser visto na Figura 1. De acordo com Morgenstern et al. (2016), a ruptura da barragem se iniciou na região do recuo. Trata-se de uma área onde é difícil estabelecer seções transversais representativas. A abordagem 2D em algumas poucas seções transversais pode não oferecer uma avaliação completa da estrutura. Por outro lado, a análise 3D é vantajosa para vales fechados, sendo o recuo uma característica adicional que reforça a sua necessidade. Além disso, a simplificação inerente de análises 2D considera a superfície de deslizamento infinita na terceira dimensão (Fredlund et al., 2017), o que claramente não se observa nessa barragem. Justifica-se, portanto, a necessidade de uma análise 3D que inclua toda a complexidade espacial dos trechos côncavos e convexos presentes.

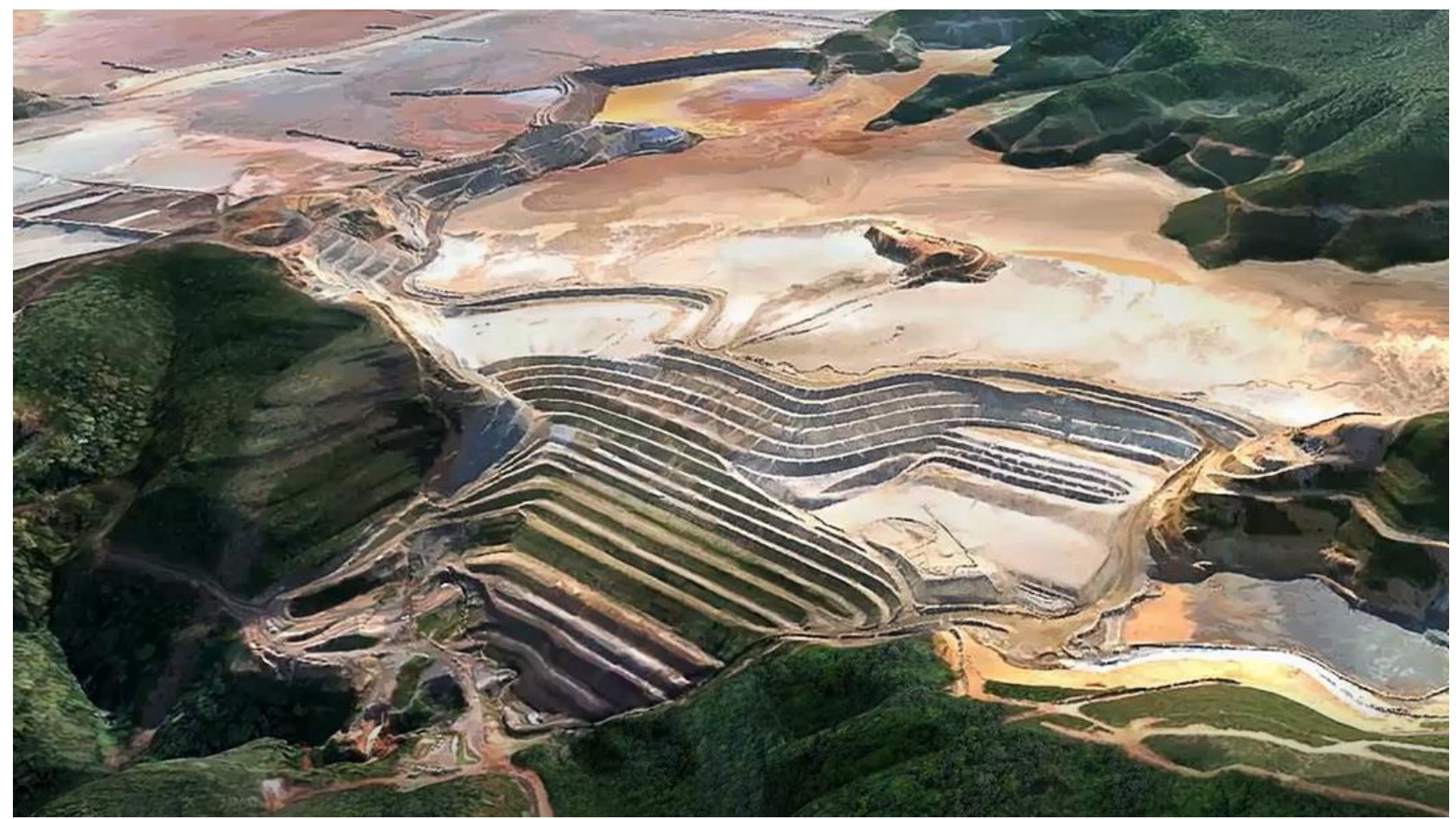

FIGURA 1: Visão geral da Barragem de Fundão (novembro de 2015). FONTE: Morgenstern et al. (2016). 
Este trabalho foi estruturado em três tópicos principais. Primeiramente, será apresentada uma breve revisão bibliográfica que fundamenta a seleção dos dados utilizados para construção do modelo $3 \mathrm{D}$ da barragem e as análises realizadas. Em seguida, serão apresentadas análises de verificação da qualidade do modelo 3D construído. Tal verificação foi realizada por meio da extração de seções transversais do modelo 3D, análise de estabilidade 2D dessas seções e comparação dos Fatores de Segurança (FS) obtidos com aqueles apresentados no relatório do Painel para as mesmas seções. Finalmente, será apresentada a análise dos dados obtidos em múltiplas seções transversais e direções de deslizamentos, seguindo abordagens 2D e 3D.

\section{HISTÓRICO DA BARRAGEM DE FUNDÃO}

O Complexo de Germano produz minério de ferro, sendo seus rejeitos depositados em barragens pelo método de alteamento a montante. Os sucessivos alteamentos por esta técnica ocorrem sobre a praia de rejeitos, o que implica que a própria praia de rejeito torna-se parte da fundação dos diques de alteamento. Maiores detalhes sobre o processo construtivo podem ser encontrados em ICOLD (1996). Dois tipos de rejeitos são produzidos no complexo, um material arenoso com boa capacidade de drenagem e um resíduo argiloso, com relativamente baixa condutividade hidráulica. A Barragem de Fundão foi projetada em 2005, de modo a armazenar os rejeitos arenosos e argilosos separadamente, privilegiando o uso de materiais arenosos em regiões mais próxima à face da barragem. A técnica de deposição de rejeitos adotada via hidráulica requer que o resíduo arenoso esteja mais próximo da face do talude afim de facilitar o processo de drenagem, aumentando a estabilidade do maciço.

De acordo com Morgenstern et al. (2016), o dique de partida foi construído utilizando enrocamentos e os sucessivos alteamentos foram construídos com o próprio rejeito. Conforme indicado por Barron (1986), normalmente os rejeitos não são materiais indicados para utilização com finalidade estrutural, pois podem apresentar elevada tendência a piping, liquefação, erodibilidade superficial e dificuldade na compactação. No entanto, por razões econômicas, é comum a utilização de rejeitos para tais fins, desde que as granulometria e composição sejam controladas e adequadas para o barramento.

O projeto envolveu a construção de outro dique, à montante do primeiro, com a finalidade de garantir a separação entre os materiais, tendo-se a deposição da lama (material argiloso) a partir deste segundo dique, distante da face da barragem. No entanto, a produção de rejeito argiloso foi, em vários momentos, superior à de material arenoso. Como resultado, materiais argilosos invadiram por diversas vezes a zona arenosa de jusante, desrespeitando a distância mínima estabelecida de $200 \mathrm{~m}$ até a face do talude. Houve registros de lama a $60 \mathrm{~m}$ da face dos taludes da barragem, principalmente na região da ombreira esquerda.

Morgenstern et al. (2016) relatam que uma série de fatores desencadeou a necessidade de se modificar a barragem durante seu alteamento. As medidas adotadas consistiam principalmente na alteração do projeto inicial do dreno de fundo. Foi construído um colchão drenante de geossintético na cota de 826 metros, conforme indicado na Figura 2(a). Admitiu-se a saturação abaixo dessa elevação.

Outro fator relevante que modificou 0 projeto da barragem foi a incapacidade estrutural das galerias abaixo da ombreira esquerda de suportar novos alteamentos. Por esse motivo, foi estabelecida uma região de recuo. A partir daí, houve uma série de registros de fissuras nessa região. Com o avanço do alteamento e os eventos de avanço indesejável da lama depositada a jusante, ocorreu o empoleiramento da água, ocasionando o aumento o nível freático (NA). Esses fatores tornaram a região do recuo mais desfavorecida do ponto de vista de estabilidade. 
As Figuras 2(b) e 2(c) mostram seções transversais típicas, com a disposição dos rejeitos na ombreira direita e na ombreira esquerda, respectivamente. A Barragem de Fundão foi construída em um vale em formato $V$ e possuía, no momento da ruptura, altura máxima de $110 \mathrm{~m}$. Destaca-se a elevação de $900 \mathrm{~m}$ da crista e a inclinação dos taludes de 3,2H:1V na ombreira direita. A região do recuo está localizada a partir da cota de $862,5 \mathrm{~m}$ e possui taludes levemente mais abatidos. Conforme ilustra a Figura 2(c), esta região possui cerca de 160 metros de comprimento e é seguida por uma berma de equilíbrio, até a cota aproximada de $877 \mathrm{~m}$.

As regiões vermelhas das Figuras 2(b) e 2(c) representam as camadas de argila. O Painel de Investigação apontou que o principal fator responsável pela falha foi a presença da argila na ombreira esquerda. A causa da ruptura foi o fenômeno de liquefação, ocasionado pelo processo de extrusão lateral de camadas de argila. O processo de extrusão resulta em esforços exercidos pelas camadas argilosas para frente e laterais, proporcionais ao peso aplicado pelas camadas superiores. O deslocamento da argila alivia o confinamento horizontal da camada arenosa e, consequentemente, provoca uma trajetória de tensões favorável ao fenômeno de liquefação. O fluxo ocorrido após a falha da barragem é consequência direta do processo de liquefação, que tem como requisitos solo sem coesão, saturado e com tendência à redução de volume devido ao cisalhamento (Pereira, 2005). Embora haja uma pequena quantidade de lama na ombreira direita, a mesma estava melhor confinada e, portanto, livre da extrusão lateral.

a)

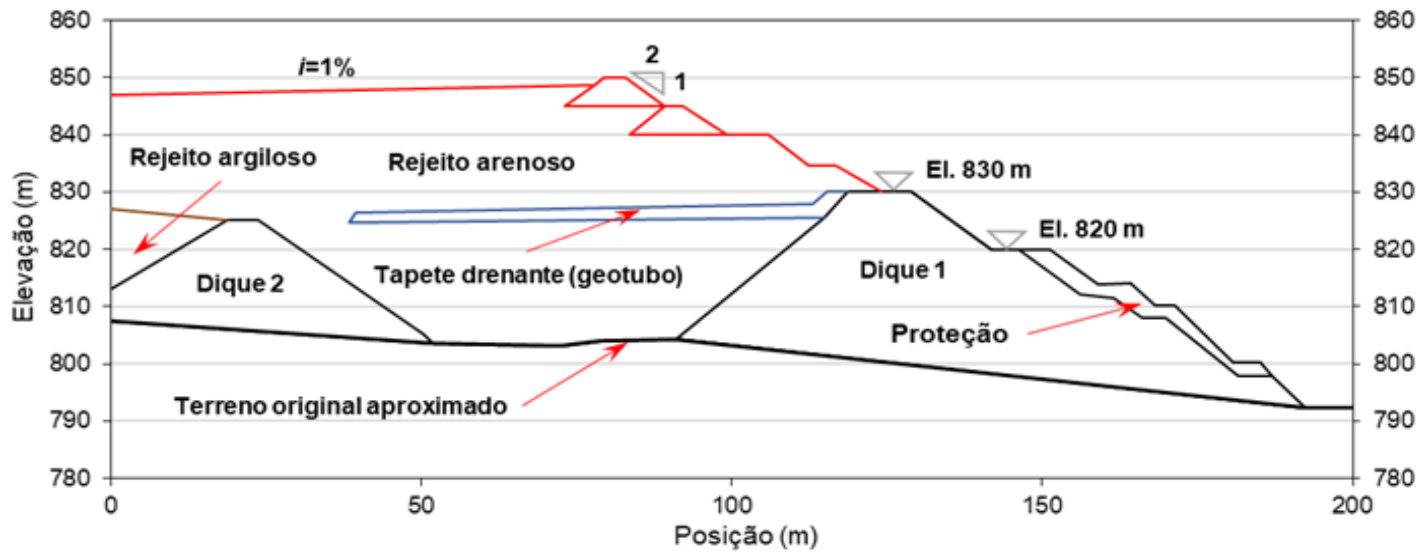

b)
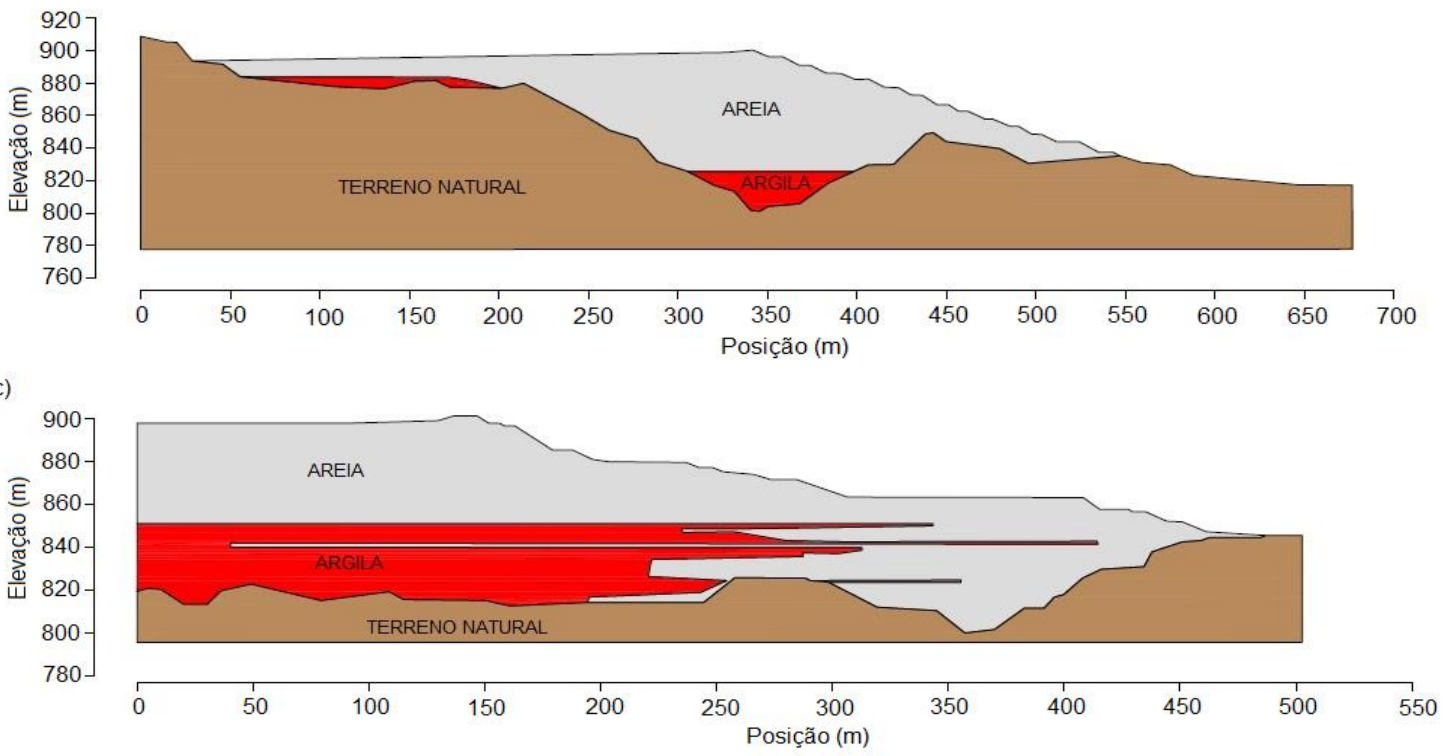

FIGURA 2: Seção transversal típica: (a) novo projeto de elevação da barragem (sem escala); (b) seção transversal de referência da ombreira direita; (c) seção transversal de referência da ombreira esquerda.

FONTE: Modificada de Morgenstern et al. (2016). 
Outro fator relevante que também pode ter colaborado com a falha foram pequenos tremores de terra ocorridos minutos antes da ruptura. Os deslocamentos gerados pela vibração podem ter provocado acréscimos de tensões que propiciaram o início do processo de extrusão lateral e o fenômeno de liquefação que culminou na ruptura da estrutura. A conclusão do Painel foi de que a ruptura da barragem de Fundão se deu pelo processo de liquefação e não por instabilidade dos taludes. A ruptura da Barragem de Fundão ocasionou sérios danos à barragem de Santarém, além de fragilizar a estrutura da barragem ao lado, de Germano.

\section{METODOLOGIA}

Os dados da barragem de Fundão utilizados nesse trabalho foram retirados, majoritariamente, do relatório elaborado pelo Painel de Investigação (Morgenstern et al., 2016), publicação de domínio público e que oferece informações sobre a geometria, propriedades e condições do maciço. Não existem, até o momento, outros relatórios publicados que ofereçam dados adicionais.

A Figura 3 apresenta o modelo 3D construído neste trabalho para a barragem. Foram utilizados os dados de doze seções transversais, permitindo estabelecer a geometria da fundação, superfície da barragem, posição dos diques, disposição de rejeitos e do sistema de drenagem ao longo da barragem. Além da interpolação entre as seções transversais, foram empregadas imagens de satélite (PhotoSat; Google Earth) que complementaram a geometria em outras regiões. Como resultado, obteve-se uma nuvem de 15.000 pontos de elevação.

Dois módulos do pacote SVOFFICE 5 (SoilVision Systems Ltd., 2018) foram utilizados para a construção e análise do modelo. O módulo SVDESIGNER possui ferramentas de manipulação de malha que foram usadas para a construção do modelo 3D e para estabelecer a superfície freática, necessária em parte das análises. O módulo
SVSLOPE foi utilizado para as análises de estabilidade 2D e 3D, incluindo a realização de análises em múltiplas seções transversais do modelo 3D.

As condições de poropressões utilizadas nas análises foram especificadas em termos de uma superfície freática. Esta superfície foi baseada em uma simulação 3D publicada pelo Painel de Investigação e nos dados de medições piezométricas fornecidos pela empresa Samarco e divulgados no relatório do Painel. Os 53 piezômetros alocados ao longo do corpo da barragem estavam, em sua maioria, em perfeitas condições.

Conforme esperado, as condições de drenagem da ombreira direita eram superiores às da ombreira esquerda. Segundo relatos apresentados pelo Painel, havia pontos de surgência de água na ombreira esquerda, evidenciando a ineficiência do sistema de drenagem. É importante ressaltar que todas as análises apresentadas nesse trabalho que fazem uso de tensões efetivas utilizam distribuições verticais de poropressões hidrostáticas, sem análise de fluxo. Ou seja, a observação dos piezômetros é interpretada de maneira simplificada. Procedimento equivalente foi adotado pelo Painel.

As propriedades de resistência ao cisalhamento estão agrupadas na Tabela 1. Os parâmetros de resistência drenada foram obtidos por meio de ensaios do tipo Triaxial CD. O parâmetro de resistência não drenada $\phi$ foi baseado em ensaios Triaxiais $\mathrm{CU}$. A razão de resistência não drenada $\left(S u / \sigma^{\prime}\right.$ ) foi determinada a partir de ensaios do tipo CPT. Foi considerado que os elementos drenantes não possuem capacidade de reforço do maciço, sendo suas propriedades de resistência desconsideradas.

$\mathrm{Na}$ literatura encontram-se relatos de que a superfície de deslizamento 3D frequentemente possui o formato próximo a um elipsoide (Adriano, 2009). Por isso, o formato de busca adotado foi um elipsoide com dimensões iguais de profundidade e largura e com 
alongamento transversal dado por uma razão chamada de aspect ratio. A análise de estabilidade de taludes foi feita pelo o Método Geral de Equilíbrio Limite das Fatias (Fredlund \& Krahn, 1977) e das Colunas (Lam \& Fredlund, 1993), métodos esses consagrados na literatura. Dentre as limitações inerentes aos métodos de equilíbrio limite, destaca-se a consideração de distribuição de tensões geostáticas que desprezam as trajetórias de geração de tensões e a redistribuição de tensões causada pelo comportamento tensão-deformação dos diferentes materiais. Além disso, a complexidade espacial dos materiais e da geometria da barragem também são fatores importantes na distribuição de tensões que são em parte ignorados nesse método de análise de estabilidade de taludes.

\section{ANÁLISES DE VERIFICAÇÃO DO MODELO}

A validação do modelo 3D da barragem foi feita extraindo duas seções do modelo completo 3D e comparando os valores de Fator de Segurança bidimensional (FS2D) obtidos desta maneira com aqueles apresentados pelo Painel de Investigação. Foram selecionadas uma seção próxima à ombreira direita e outra próxima à ombreira esquerda. O critério de validação foi que, se valores de FS2D semelhantes fossem obtidos, a geometria 3D obtida seria uma boa representação do problema. Durante toda a primeira fase de análises foi utilizada a opção de otimização das superfícies de ruptura com 1000 iterações.

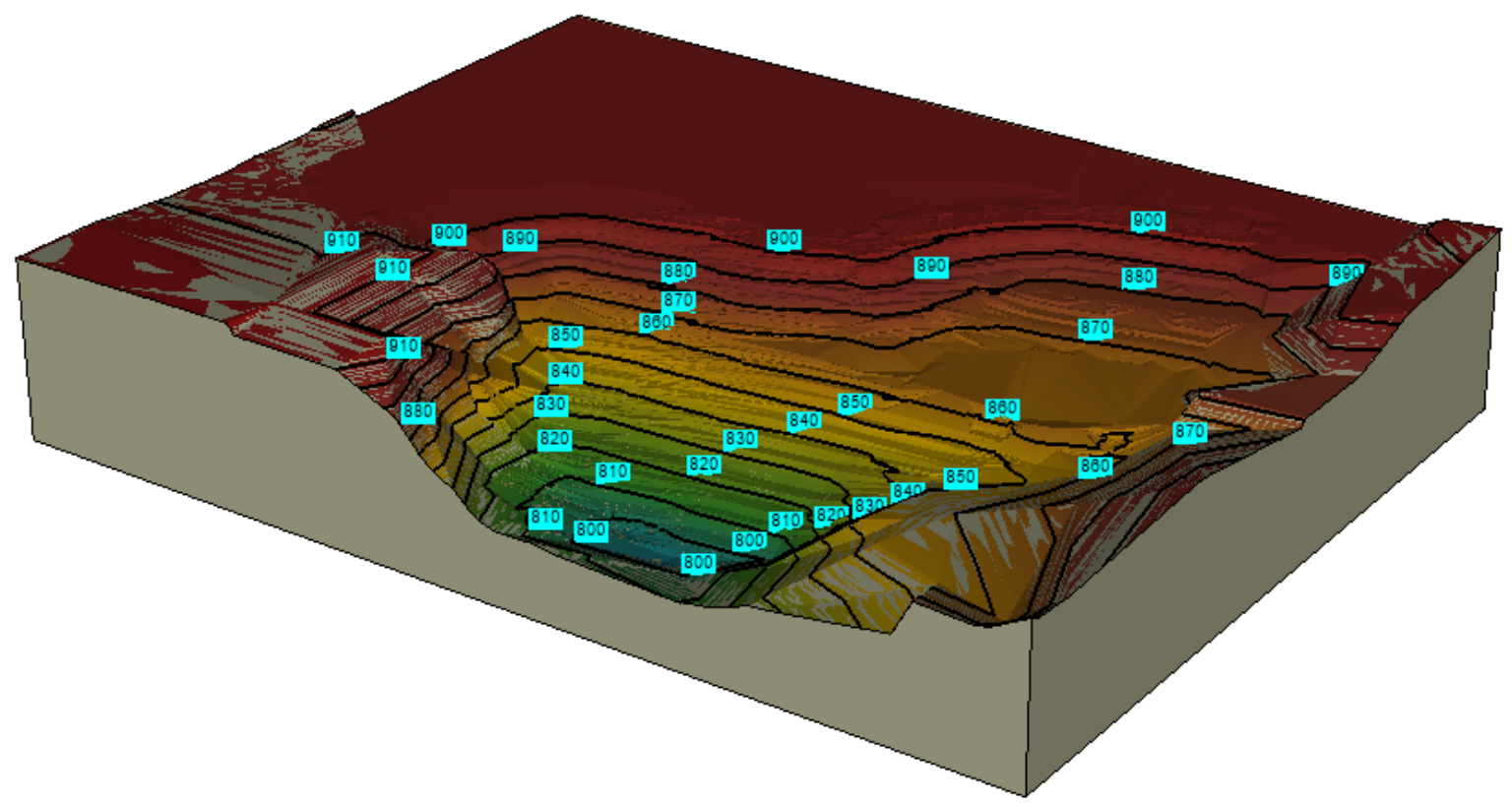

FIGURA 3: Vista do modelo 3D da Barragem de Fundão. FONTE: Autoria própria.

\begin{tabular}{|c|c|c|c|c|c|}
\hline & \multicolumn{3}{|c|}{ RESISTÊNCIA DRENADA } & \multicolumn{2}{|c|}{ RESISTÊNCIA NÃO DRENADA } \\
\hline & $\begin{array}{c}\text { Peso } \\
\text { específico, } \gamma \\
\left(\mathrm{kN} / \mathrm{m}^{3}\right) \\
\end{array}$ & $\begin{array}{c}\text { Ângulo de atrito } \\
\text { efetivo, } \phi^{\prime} \\
\left({ }^{\circ}\right)\end{array}$ & $\begin{array}{c}\text { Coesão } \\
\text { efetiva, } c^{\prime} \\
(\mathrm{kPa}) \\
\end{array}$ & $\begin{array}{c}\text { Ângulo de } \\
\text { atrito total, } \phi \\
\left({ }^{\circ}\right) \\
\end{array}$ & $\begin{array}{c}\text { Razão de } \\
\text { resistência, Su/ } \sigma_{v}^{\prime} \\
(\mathrm{kPa})\end{array}$ \\
\hline Fundação de filito & 22 & 32 & 40 & - & - \\
\hline Dique de enrocamento & 22 & 45 & 0 & - & - \\
\hline Rejeito argiloso & 22 & 28 & 5 & 16 & 0,25 \\
\hline Rejeito arenoso & 22 & 33 & 0 & 16 & 0,25 \\
\hline
\end{tabular}


A Tabela 2 agrupa os resultados referentes à seção da ombreira direita. Os valores de FS2D obtidos apresentam-se próximos aos encontrados pelo Painel na condição drenada, sendo o método de busca path search aquele que encontrou o menor valor de FS2D, igual a 1,869. Tem-se, nesse caso, uma diferença de apenas $2,2 \%$ em relação ao valor de referência apresentado pelo Painel. Esse resultado permite concluir que o modelo 3D construído nesse trabalho representa adequadamente a geometria da barragem nessa região.

A análise da barragem em condições não drenadas resultou em valores de FS2D inferiores aos obtidos pelo Painel, com diferenças entre 20,8 e 24,0\%. A diferença observada se deve à forma como a resistência ao cisalhamento foi representada. As análises do Painel consideraram resistência não drenada abaixo da linha freática e resistência drenada acima da mesma. A hipótese de condição drenada acima de linha freática se deve à consideração de que solos não saturado apresentariam comportamento de materiais secos, sem excesso de poropressão. No caso das análises realizadas nesse trabalho, foi adotada resistência não drenada em todo o maciço, independentemente da posição em relação à linha freática, levando às diferenças observadas.

A Tabela 3 agrupa os resultados dos FS2D obtidos para a seção da ombreira esquerda. Adotou-se a hipótese de que a superfície composta percorreria o material mais fraco, argila. Nessa seção transversal destaca-se a presença das camadas de argila, talude com inclinação mais branda e altura menor do talude. Tais características resultam em valores de FS2D maiores do que os da ombreira direita. A Tabela 3 mostra que os valores obtidos com o modelo construído neste trabalho se apresentam próximos aos de referência. As divergências maiores se devem à dificuldade de modelar as camadas de argila e da linha piezométrica. A diferença máxima foi encontrada com os parâmetros drenados, sendo de $12,2 \%$.

TABELA 2: Fatores de Segurança bidimensionais (FS2D) obtidos para ombreira direita.

\begin{tabular}{|c|c|c|c|c|}
\hline CENÁRIO & $\begin{array}{l}\text { MÉTODO DE BUSCA } \\
\text { DE SUPERFÍCIE } \\
\text { CRÍTICA }\end{array}$ & $\begin{array}{l}\text { FORMATO DA } \\
\text { SUPERFÍCIE DE } \\
\text { RUPTURA }\end{array}$ & $\begin{array}{l}\text { FS OBTIDO } \\
\text { PELOS } \\
\text { AUTORES }\end{array}$ & $\begin{array}{l}\text { FS OBTIDO POR } \\
\text { MORGENSTERN et } \\
\text { al. (2016) }\end{array}$ \\
\hline \multirow{4}{*}{$\begin{array}{l}\text { Parâmetros de resistência } \\
\text { drenada }\end{array}$} & Grid and Tangent & Circular composta & 1,879 & \multirow{4}{*}{1,91} \\
\hline & Slope Search & Circular composta & 1,887 & \\
\hline & Block Search & Não circular & 1,874 & \\
\hline & Path Search & Não circular & 1,869 & \\
\hline \multirow{2}{*}{$\mathrm{Su} / \sigma^{\prime}{ }_{v}$ igual a 0,25} & Grid and Tangent & Circular composta & 0,809 & \multirow{2}{*}{1,00} \\
\hline & Path Search & Não circular & 0,808 & \\
\hline \multirow{2}{*}{$\begin{array}{c}\phi \text { do rejeito arenoso igual } \\
\text { a } 16^{\circ}\end{array}$} & Grid and Tangent & Circular composta & 0,909 & \multirow{2}{*}{1,04} \\
\hline & Path Search & Não circular & 0,861 & \\
\hline
\end{tabular}

FONTE: Autoria própria.

TABELA 3: Fatores de Segurança bidimensionais (FS2D) obtidos para ombreira esquerda.

\begin{tabular}{|c|c|c|c|c|}
\hline CENÁRIO & $\begin{array}{c}\text { MÉTODO DE BUSCA } \\
\text { DE SUPERFÍCIE } \\
\text { CRÍTICA }\end{array}$ & $\begin{array}{l}\text { FORMATO DA } \\
\text { SUPERFÍCIE DE } \\
\text { RUPTURA }\end{array}$ & $\begin{array}{l}\text { FS OBTIDO } \\
\text { PELOS } \\
\text { AUTORES }\end{array}$ & $\begin{array}{l}\text { FS OBTIDO POR } \\
\text { MORGENSTERN et } \\
\text { al. (2016) }\end{array}$ \\
\hline \multirow{5}{*}{$\begin{array}{l}\text { Parâmetros de resistência } \\
\text { drenada }\end{array}$} & Grid and Tangent & Circular composta & 2,659 & \multirow{5}{*}{2,88} \\
\hline & Slope Search & Circular composta & 2,708 & \\
\hline & Block & Não circular & 2,566 & \\
\hline & Greco Search & Não circular & 2,745 & \\
\hline & Path Search & Não circular & 2,619 & \\
\hline \multirow{2}{*}{$\mathrm{Su} / \sigma^{\prime}{ }_{v}$ igual a 0,25} & Grid and Tangent & Circular composta & 1,084 & \multirow{2}{*}{-} \\
\hline & Path Search & Não circular & 1,056 & \\
\hline \multirow{2}{*}{$\begin{array}{l}\phi \text { do rejeito arenoso igual } \\
\qquad \text { a } 16^{\circ} \\
\end{array}$} & Grid and Tangent & Circular composta & 1,173 & \multirow{2}{*}{1,28} \\
\hline & Path Search & Não circular & 1,153 & \\
\hline
\end{tabular}


Finalmente, pode-se afirmar que as superfícies críticas obtidas foram próximas às apresentadas pelo painel, corroborando as observações quanto aos valores dos fatores de segurança. Tendo-se obtido resultados favoráveis nas seções replicadas, concluiu-se que o modelo construído representa adequadamente a geometria da barragem nessas regiões. Mesmo considerando a complexidade da geometria da estrutura, tem-se um forte indicativo de que os resultados obtidos nas análises posteriores, em múltiplas seções 2D e em 3D, serão representativas da condição de campo.

\section{ANÁLISES 2D EM MÚLTIPLAS SEÇÕES}

A segunda etapa do estudo consiste em uma varredura dos valores de FS2D ao longo de todo o eixo da barragem. A geometria 3D construída nesta pesquisa permitiu a extração de numerosas seções transversais, permitindo-se avaliar de maneira minuciosa como varia o FS2D ao longo das diferentes zonas, incluindo as seções em regiões côncava e convexas.

A Figura 4 apresenta a disposição de 77 seções transversais construídas para análises 2D. As seções transversais foram construídas a partir do modelo 3D, por meio da ferramenta multiplane analysis disponível no programa SVSLOPE. A avaliação de múltiplas seções é uma maneira aperfeiçoada de realizar análises 2D, já que a Barragem de Fundão não permite estabelecer uma única seção representativa. As seções 2D foram obtidas em intervalos de $10 \mathrm{~m}$ e analisadas por meio de métodos de busca de superfície crítica baseados em técnicas de otimização, Slope search, Greco search e Path search. Detalhes a respeito dos métodos de busca podem ser encontrados em SoilVision Systems Ltd. (2018). É importante ressaltar que efeitos 3D não são considerados na análise multiplane. Tem-se, na verdade, uma mais refinada descrição da evolução do FS2D ao longo de toda a estrutura.

A Figura 5 apresenta os valores de FS2D obtidos ao longo do eixo da barragem, da ombreira direita até a esquerda, pelos três métodos de busca. Para todas as condições de resistência e métodos de busca, o valor mínimo de FS2D é encontrado na região convexa (entre 200 e $350 \mathrm{~m}$ ), principalmente devido ao aumento da altura da barragem. Após a região convexa, caminhando em direção à ombreira esquerda, os valores de FS crescem devido à menor altura e ao abatimento do talude e graças à presença da berma de equilíbrio no trecho final.

Considerando os parâmetros de resistência drenada, verifica-se que a ombreira esquerda possui valores de FS2D cerca de $36 \%$ maiores que os observados na ombreira direita. Os menores fatores de segurança obtidos são 1,80 pelo método slope search, 1,77 pelo método path search e 1,76 pelo método Greco search. O método Greco search encontrou dificuldades em 20 seções, seja não convergindo, seja obtendo valores de FS2D muito elevados, incoerentes com os obtidos pelos demais métodos. As superfícies de ruptura críticas encontradas pelo método Path search possuem frequentemente valores de FS2D ligeiramente menores do que os obtidos pelo método Slope search. Conclui-se que o método Path search adequou-se melhor à análise de estabilidade de taludes ao longo do eixo da barragem. Por isso, esse foi o único método utilizado para a análise com parâmetros de resistência não drenada.

Verificou-se que os resultados obtidos considerando condições não drenadas possuem influência das condições de geometria semelhantes às análises com resistência drenada, porém com menores diferenças ao longo do eixo. Obviamente, os valores de fator de segurança são significativamente inferiores, atingindo aproximadamente 1,0. Considerando o FS2D médio ao longo do eixo da barragem, observa-se que o valor na condição não drenada é 49,6\% menor que no cenário drenado.

A partir das análises 2D, a região mais suscetível ao deslizamento, em teoria, seria a 
ombreira direita, com fator de segurança para a condição não drenada menor do que 1. Por outro lado, a ruptura foi iniciada na ombreira esquerda. Desta forma, constata-se que a análise de estabilidade, por si só, não explica o motivo da ruptura ter começado na ombreira esquerda, sendo para isso necessário identificar outros mecanismos de instabilização, conforme apresentado pelo Painel de Investigação. Pode-se inferir também que a provável condição real do maciço no momento da ruptura deveria ser drenada ou, na pior das hipóteses, intermediária entre a condição não drenada e a condição drenada. O Painel de Investigação indicou que condições drenadas teriam prevalecido, já que a ruptura não se iniciou próxima da ombreira direita, onde os taludes são mais íngremes e o alteamento se deu de forma mais acelerada.

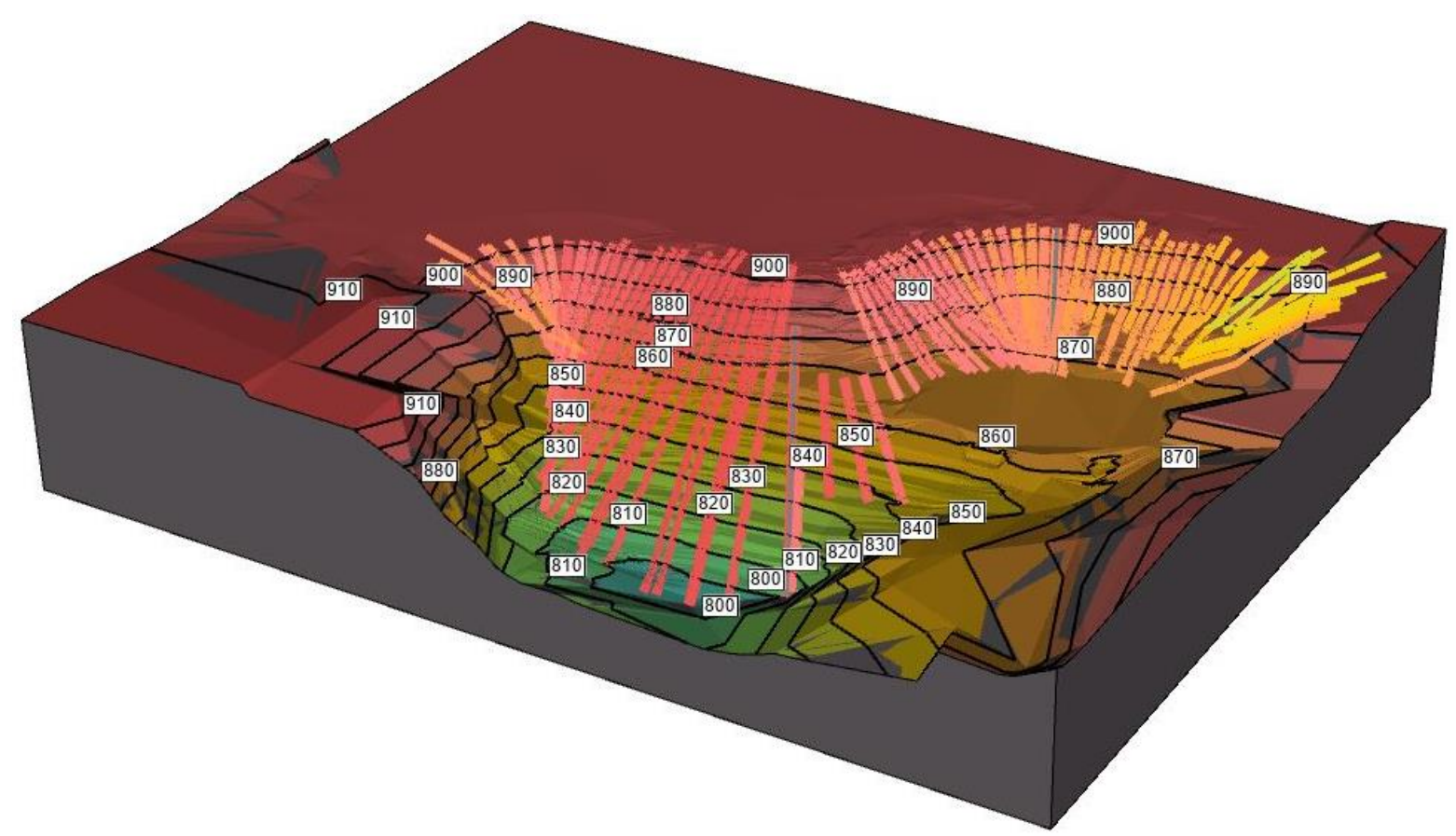

FIGURA 4: Disposição espacial das seções transversais para parâmetros drenados em análises multiplane. FONTE: Autoria própria.

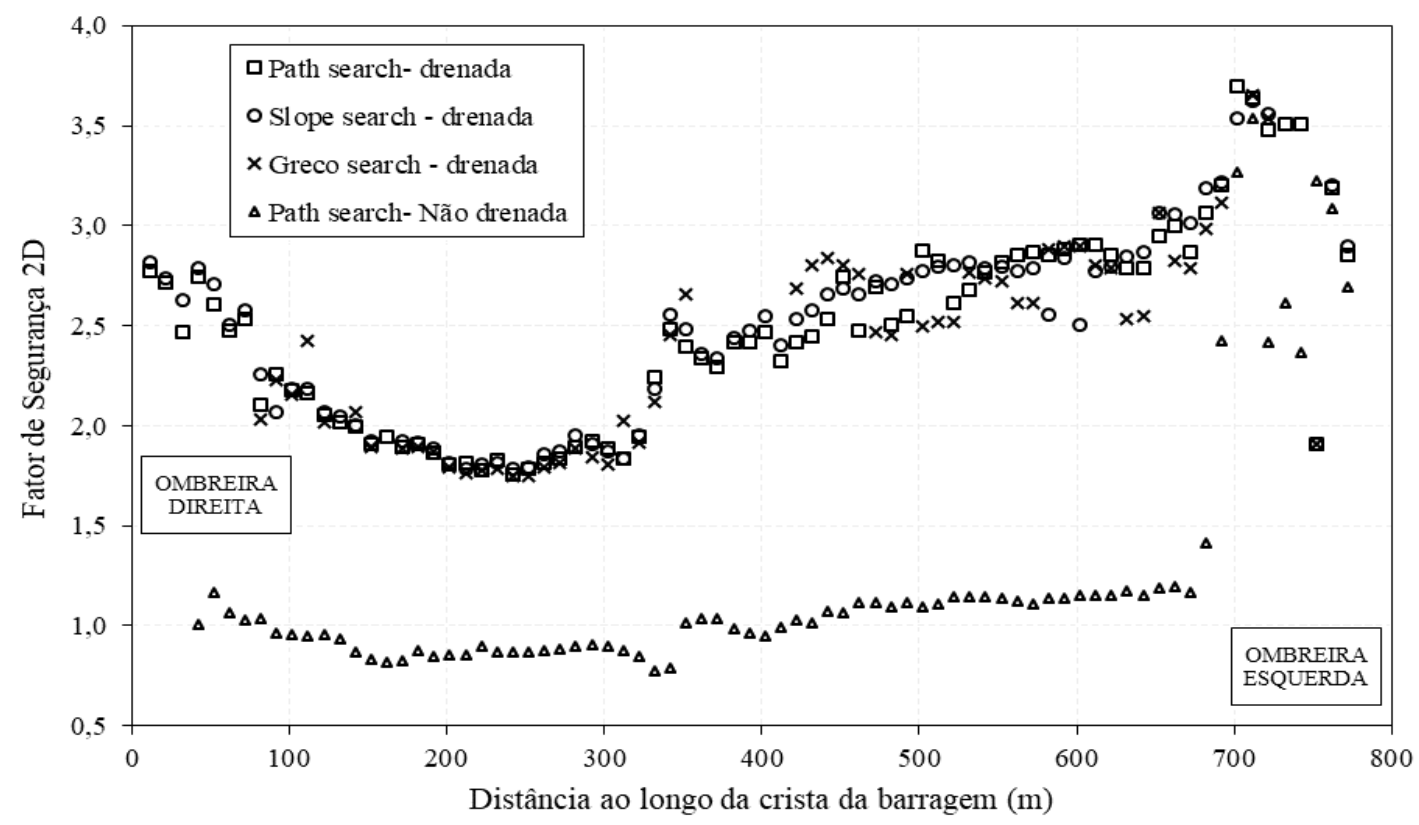

FIGURA 5: Fatores de Segurança bidimensionais (FS2D) obtidos através das análises multiplane. FONTE: Autoria própria. 


\section{ANÁLISES 3D EM MÚLTIPLAS DIREÇÕES DE DESLIZAMENTOS}

A Figura 6 apresenta as direções de deslizamentos utilizadas para a abordagem 3D. As análises 3D consistem em 15 direções de deslizamento igualmente espaçadas, a cada $45 \mathrm{~m}$. A análise 3D utilizou parâmetros de resistência drenada e não drenada, com Su/ $\sigma^{\prime}{ }_{v}$ igual a 0,25. 0 método de busca de superfície crítica utilizado nas análises 3D foi o Slope Search. Neste método é especificada uma região de busca baseada em trechos de entrada e saída da superfície de deslizamento e faixa de valores de aspect ratio. Combinações aleatórias de coordenadas de entrada e saída e de aspect ratio são realizadas, observando um total especificado de combinações. Neste trabalho adotou-se um total de 1500 superfícies. A Tabela 4 reúne os resultados das análises 3D, indicando as quantidades de colunas ativas, o volume de solo correspondente à superfície crítica e os FS's em cada direção de deslizamento. A grande variabilidade de quantidade de colunas ativas indica variações nas dimensões das superfícies de deslizamento.

A Figura 7 traz as superfícies críticas, considerando a resistência drenada, localizadas na ombreira esquerda e nas direções 07, 09, 11 e 15.

A direção 15 apresenta uma superfície de ruptura relativamente pequena e superficial, condicionada pela proximidade da fundação, mais resistente. Os valores de Fator de Segurança tridimensional (FS3D) dessa e das próximas direções de deslizamento foram os que apresentaram valores menores e até inferiores aos das análises 2D. A direção 11 retrata a região em que de fato houve a ruptura da barragem e na qual observa-se de maneira mais significativa a influência da presença de lama. O FS3D foi 2,946, valor superior ao encontrado nas seções abrangidas na análise 2D. A direção 09 apresenta um FS3D mais elevado, o que se deve ao fato de que a distribuição de tensões em regiões côncavas produz condições mais estáveis (Domingos, 2016). O FS3D é cerca de 8,3\% maior que o FS2D médio das seções transversais presentes nessa região.

A Figura 8 traz superfícies críticas localizadas na ombreira direita, nas direções 04 e 02. A direção 04 está localizada na região da barragem em que não há a presença de camadas de rejeitos argilosos. Observa-se na direção 04 uma ampla superfície de ruptura, com elevado aspect ratio e profundidade rasa, característica comum de solos em que há predominância de resistência por atrito. O FS3D obtido, igual a 2,106, apresentou o menor valor. O FS3D é cerca de 17\% maior que a média dos valores nessa região do talude observados na análise 2D.

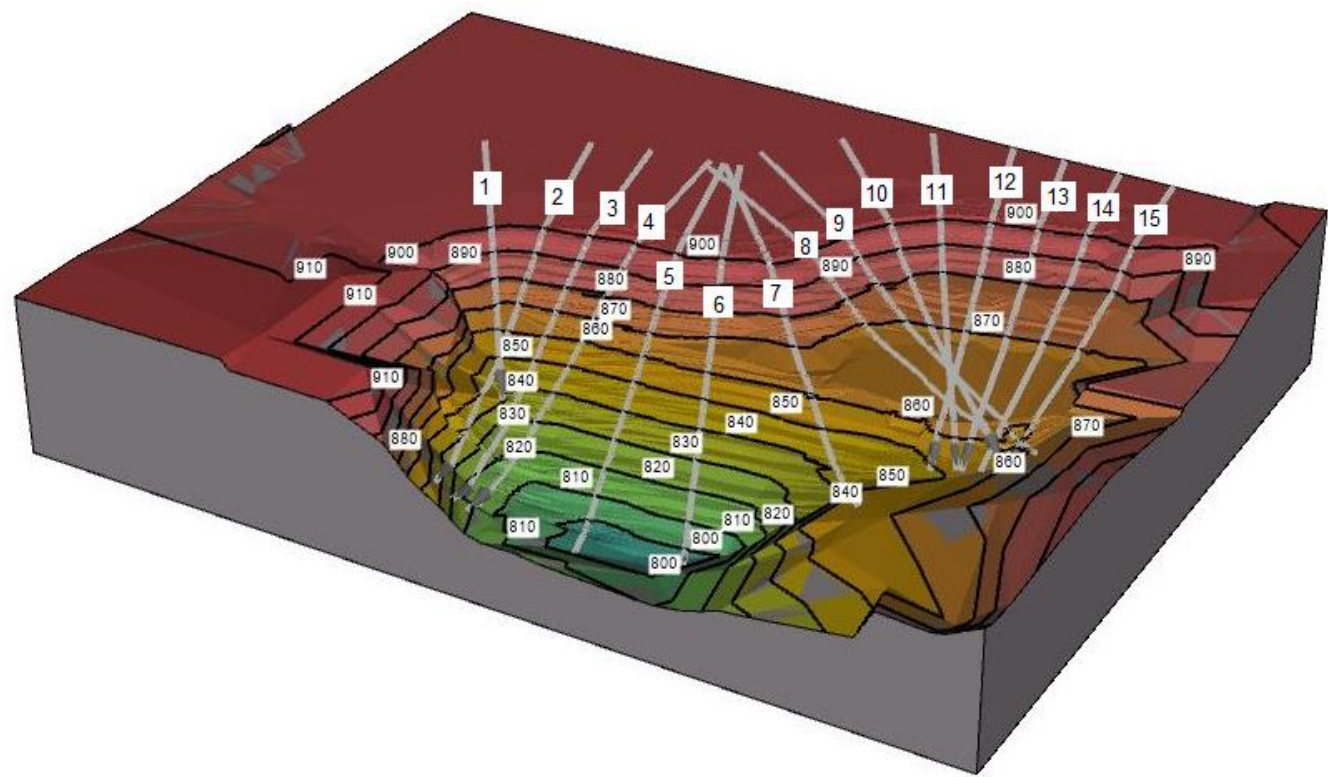

FIGURA 6: Direções de ruptura utilizadas para as análises 3D.

FONTE: Autoria própria, 2017. 


\begin{tabular}{|c|c|c|c|c|c|c|}
\hline \multirow[b]{2}{*}{$\begin{array}{l}\text { DIREÇÃO DA } \\
\text { RUPTURA }\end{array}$} & \multicolumn{3}{|c|}{ Parâmetros de resistência drenada } & \multicolumn{3}{|c|}{ Parâmetros de resistência não drenada } \\
\hline & $\begin{array}{c}\text { TOTAL DE } \\
\text { COLUNAS } \\
\text { ATIVAS }\end{array}$ & $\begin{array}{l}\text { VOLUME } \\
\text { TOTAL }\left(\mathrm{m}^{3}\right)\end{array}$ & $\begin{array}{c}\text { FATOR DE } \\
\text { SEGURANÇA 3D }\end{array}$ & $\begin{array}{c}\text { TOTAL DE } \\
\text { COLUNAS } \\
\text { ATIVAS }\end{array}$ & $\begin{array}{l}\text { VOLUME } \\
\text { TOTAL }\left(\mathrm{m}^{3}\right)\end{array}$ & $\begin{array}{c}\text { FATOR DE } \\
\text { SEGURANÇA 3D }\end{array}$ \\
\hline 1 & 361 & 65400 & 3,346 & 361 & 112000 & 1,430 \\
\hline 2 & 376 & 198500 & 2,727 & 356 & 164200 & 1,253 \\
\hline 3 & 361 & 78110 & 2,317 & 364 & 82810 & 0,902 \\
\hline 4 & 408 & 64290 & 2,103 & 395 & 86330 & 0,881 \\
\hline 5 & 1915 & 2369000 & 2,140 & 435 & 701900 & 0,898 \\
\hline 6 & 881 & 348800 & 2,281 & 447 & 101600 & 0,919 \\
\hline 7 & 432 & 180900 & 2,608 & 449 & 183500 & 1,035 \\
\hline 8 & 403 & 176400 & 2,757 & 551 & 187300 & 1,109 \\
\hline 9 & 439 & 166300 & 2,871 & 777 & 392500 & 1,188 \\
\hline 10 & 914 & 764600 & 3,036 & 1000 & 846300 & 1,202 \\
\hline 11 & 520 & 493000 & 3,062 & 889 & 554700 & 1,239 \\
\hline 12 & 422 & 88360 & 2,726 & 476 & 99590 & 1,070 \\
\hline 13 & 372 & 85420 & 2,518 & 479 & 81520 & 1,006 \\
\hline 14 & 425 & 181700 & 2,700 & 386 & 42700 & 1,021 \\
\hline 15 & 389 & 141300 & 3,237 & 381 & 127400 & 1,416 \\
\hline
\end{tabular}

FONTE: Autoria própria.

a)

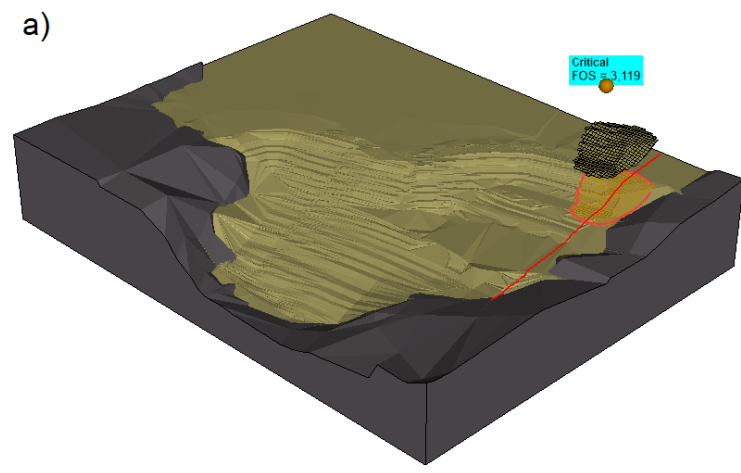

c)

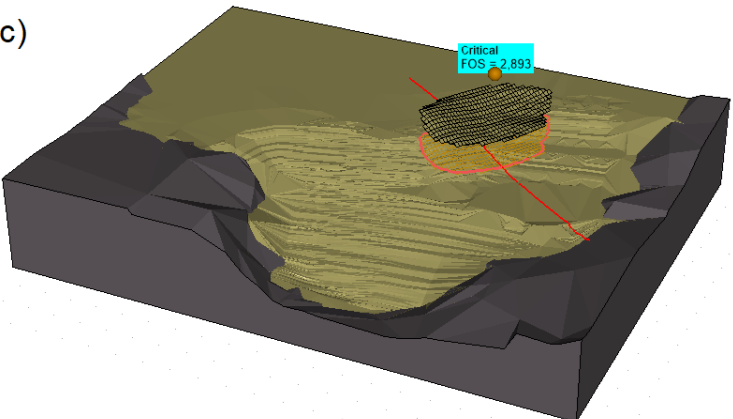

b)

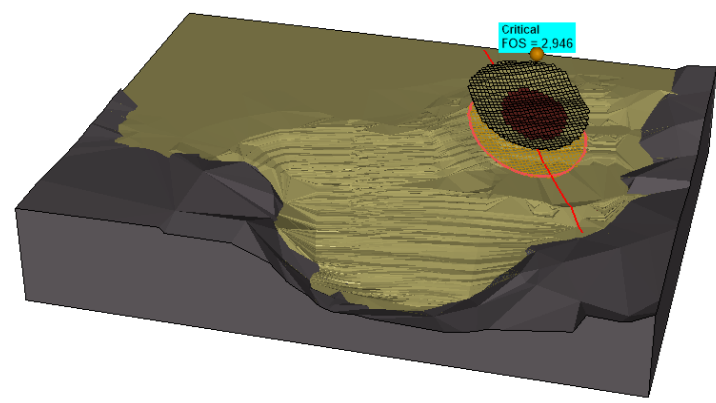

d)

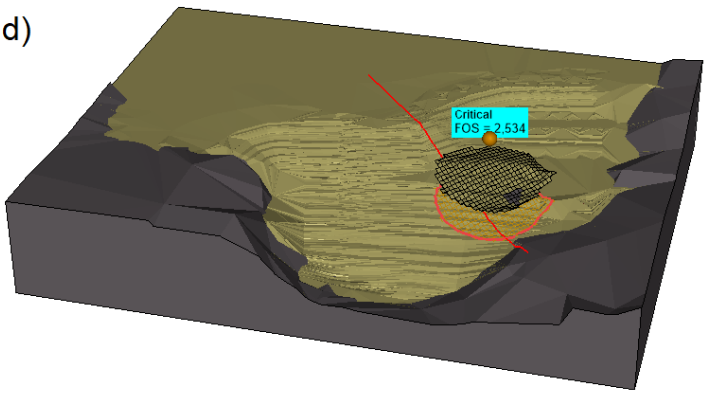

FIGURA 7: Superfícies de ruptura com parâmetros drenados próximas da ombreira esquerda da barragem, nas direções: a) 15; b) 11; c) 09; e d) 07.

FONTE: Autoria própria. 
a)

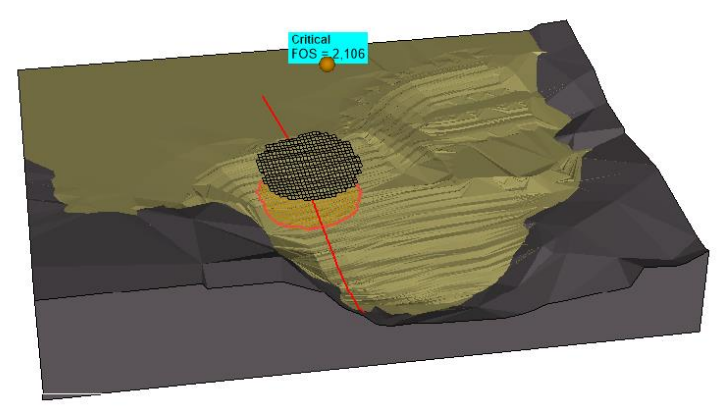

b)

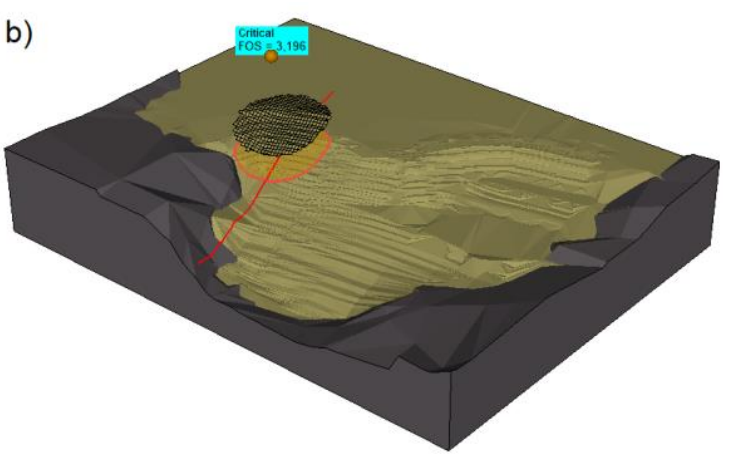

FIGURA 8: Superfícies de ruptura com parâmetros drenados próximas da ombreira direita da barragem, nas direções: (a) 04 e (b) 02.

FONTE: Autoria própria.

A direção de ruptura 07, representando a região convexa da barragem, apresentou fator de segurança idêntico ao obtido na análise 2D. Nessa superfície de deslizamento é notável a influência do elevado nível da água na região. A superfície de deslizamento 3D, nesse caso, possui as bordas influenciadas pelo empoleiramento da água e o elevado NA, incorporando todas as peculiaridades do modelo. Observa-se que a superfície de deslizamento 2D está parcialmente saturada, enquanto que as bordas da superfície $3 D$ se encontram totalmente abaixo do lençol freático. Essas características evidenciam vantagens da análise 3D em projetos que envolvem complexa topografia, condições de resistência dos materiais e poropressões (Stark \& Eid, 1998). Na direção 02, muito próximo da ombreira direita e com rejeitos pouco profundos, há forte influência do terreno original, muito mais resistente que o rejeito. Como resultado, tem-se uma pequena superfície crítica.

A Figura 9 faz a comparação entre os valores de FS2D e FS3D ao longo do eixo da barragem, para parâmetros de resistência drenada e não drenada. Vários autores afirmam que, usualmente, espera-se fatores de segurança maiores para uma análise 3D que para sua correspondente análise 2D (Lam \& Fredlund, 1993; Arellano \& Stark, 2000). No entanto, no caso da complexa geometria da barragem de Fundão, existem regiões em que os valores de FS3D são menores que os de FS2D. Na região acima da berma de equilíbrio e na região convexa da barragem, isso se mostra de maneira clara. Isso se deve à comparação de direções de deslizamento diferentes e à complexidade da posição do lençol d'água na barragem. Além disso, a região da berma de equilíbrio com seção quase constante apresenta superfícies de deslizamento com elevado aspect ratio e bastante superficiais, quando comparadas com a análise 2D. Finalmente, observa-se que o comportamento do fator de segurança ao longo do eixo da barragem é semelhante para as mesmas análises, com diferentes parâmetros de resistência.

\section{CONCLUSÕES}

Nesse estudo realizou-se a análise de estabilidade da ruptura da Barragem de Fundão utilizando abordagens 2D e 3D. Os resultados encontrados foram comparados com o relatório de Morgernstern et al. (2016). A análise 2D realizada pelo o Painel traz resultados de apenas duas seções transversais, próximas às ombreiras da estrutura. Isso não contempla as peculiaridades da geometria da barragem e não indica o comportamento da região côncava e convexa da barragem. Além do mais, a complexidade das condições internas da barragem são consideráveis, destacando-se a presença de camadas de rejeito intercaladas com as de areia, além de uma linha piezométrica muito variável ao longo da estrutura. Desta maneira, há uma significativa influência das regiões vizinhas na estabilidade de uma seção. 


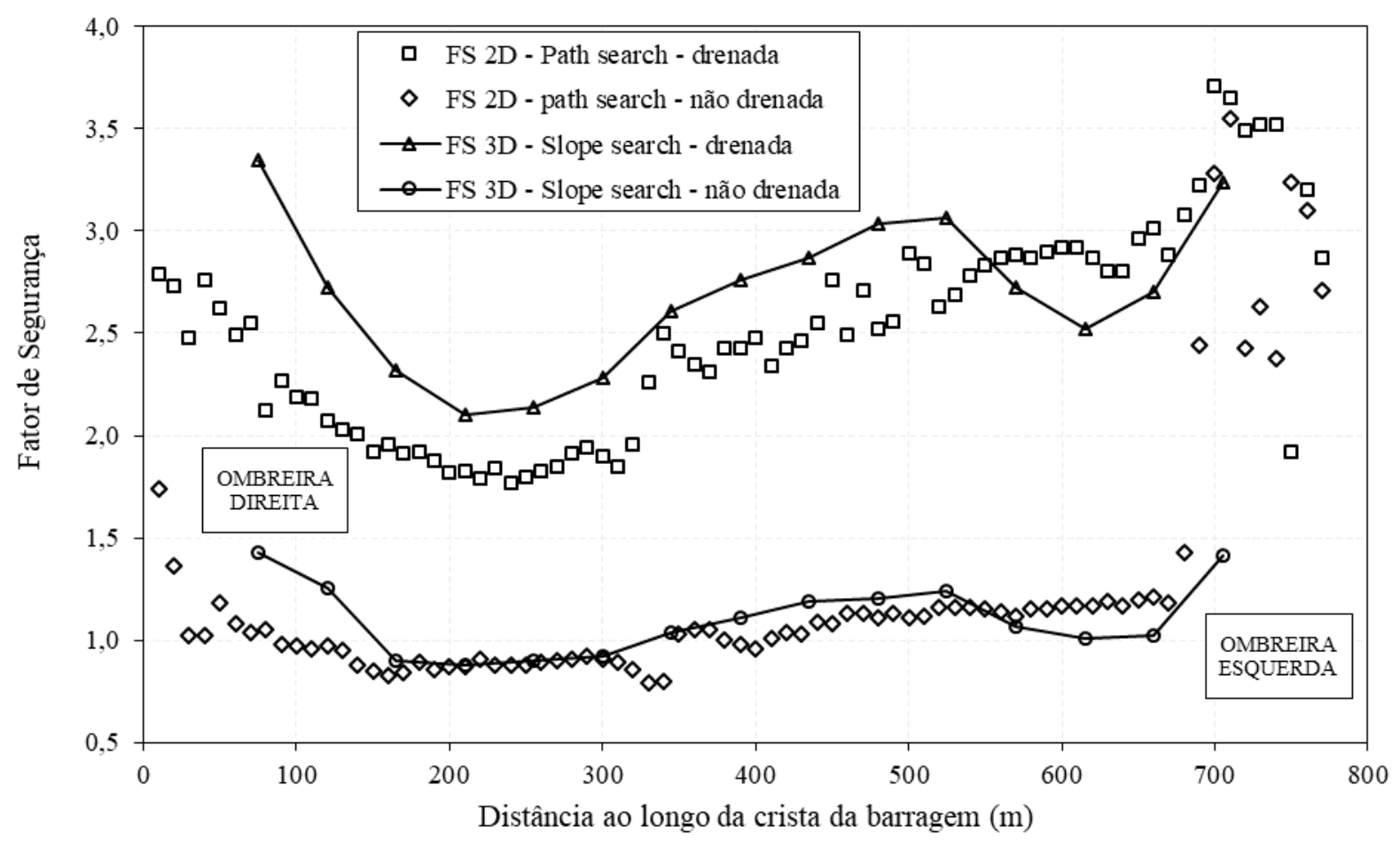

FIGURA 9: Fator de Segurança 2D e 3D ao longo do eixo da barragem FONTE: Autoria própria.

Com base nesse estudo, verificou-se que os valores de FS2D tiveram bastante variabilidade ao longo do eixo da barragem, sendo os mais críticos localizados próximos à ombreira direita. Verificou-se que os parâmetros de resistência drenada produziram valores de FS muito elevados, de forma a descartar a instabilidade de taludes como causa da ruptura nessa condição de drenagem. Por outro lado, a região convexa exige especial atenção, já que o NA se encontrava muito elevado devido à presença das camadas de argila. Nas regiões com a seção transversal do talude com eixo retilíneo os valores de FS3D apresentaram-se maiores do que os valores de FS2D, com uma diferença na ordem de $10 \%$.

Ressalta-se a necessidade de utilizar uma abordagem 3D no caso da barragem de Fundão. Os recursos computacionais da atualidade passaram a permitir análises 3D mais abrangentes, com tempos de processamento razoáveis. Por mais que a instabilidade de taludes por mecanismos convencionais não seja a provável causa iniciadora da ruptura, é importante estabelecer o efeito da geometria 3D na estabilidade.

\section{REFERÊNCIAS}

Adriano, P. R. R. Análise Tridimensional de Estabilidade de Taludes utilizando o Método Aperfeiçoado. Tese (Mestrado em Engenharia Civil) - Universidade Federal de Goiás, PPG-GECON. Goiânia, GO, 2009, p. 156.

Arellano, D.; Stark, T. D. Importance of ThreeDimensional Slope Stability Analyses in Practice. In: SLOPE STABILITY 2000, GSP no. 101, Reston, VA: ASCE, 2000, p. 18-32.

Barron, K. Waste Embankment. Edmonton, University of Alberta, Mining Engineering Department, 1986.

Chen, R. H.; Chameau, J. L. Three-Dimensional Limit Equilibrium Analysis of Slopes. Géotechnique, Vol. 32, n. 1,1982 , p. 31-40.

Domingos, H. D. Análise Tridimensional de Estabilidade de Taludes utilizando o Método de Equilíbrio Limite. Tese (Mestrado em Engenharia Civil) - Universidade Federal de Goiás, PPG-GECON. Goiânia, GO, 2016, p. 88.

Divino, P. L. Comportamento de Enrocamentos em Barragens-Estudo de Caso da Barragem de Emborcação. Tese (Mestrado em Engenharia Geotécnica) - Universidade Federal de Ouro Preto, PPGEG. Ouro Preto, MG, 2010, p. 188.

Ferreira, A. C.; Lima, V. L. A.; Medeiros, J. X.; Baracuhy, J. G. Desempenho entre Materiais Alternativos de Drenagem Subterrânea. Educação Agrícola Superior, Vol. 24, 2009, p.27. 
Fredlund, M. D.; Lu, H.; Ivkovic, Z. Practical Methodology for Transitioning to a 3D Stability Analysis for Geotechnical Consultants. A SoilVision White Paper, 2017, p. 1-12.

ICOLD - International Commission on Large Dams. A Guide to Tailings Dams and Impoundments: Design, Construction, Use and Rehabilitation. Bulletin 106, 1996, p. 244.

Lam, L. A.; Fredlund, D. G. General Limit Equilibrium Model for Three-Dimensional Slope Stability Analysis. Canadian Geotechnical Journal, Vol. 30, 1993, p. 905919.

Morgenstern, N. R.; Vick, G. S.; Viotti, C.; Watts, D. B. Cleary Gottlieb. Fundão Tailings Dam Review Panel. Report on the Immediate Causes of the Failure of the Fundão Dam, 2016, p. 88.

Pereira, E. L. Estudo do Potencial de Liquefação de Rejeitos de Minério de Ferro Sob Carregamento Estático. Tese (Mestrado em Engenharia Geotécnica) Universidade Federal de Ouro Preto, PPGEG. Ouro Preto, MG, 2005, p. 210.

Vale. Qual a importância da mineração para a economia do país? Disponível em: http://www.vale.com/brasil/pt/aboutvale/news/pagi nas/qual-a-importancia-da-mineracao-para-aeconomia-do-pais.aspx. Acesso em: 20 de novembro de 2017.

Terzaghi, K.; Peck, R. B.; Mesri, G. Soil Mechanics in Engineering Practice. John Wiley \& Sons, New York, USA, 1993.

SoilVision Systems Ltd. SVOFFICE 5 Help Manual 04/17/2018. Saskatoon, SK, Canada, 2018.

Stark, T. D.; Eid, H. T. Performance of ThreeDimensional Slope Stability Methods in Practice. Journal of Geotechnical and Geoenvironmental Engineering, Vol. 124, 1998, p. 1049-1060. 